\title{
Impact of maternal ART on mother-to-child transmission (MTCT) of HIV at six weeks postpartum in Rwanda
}

\author{
Placidie Mugwaneza', Alexandre Lyambabaje ${ }^{2}$, Aline Umubyeyi ${ }^{2}$, James Humuza², Landry Tsague ${ }^{3}$, \\ Fabian Mwanyumba ${ }^{4}$, Vincent Mutabazi ${ }^{1}$, Sabin Nsanzimana' ${ }^{1}$, Muhayimpundu Ribakare', Ange Irakoze ${ }^{1}$, \\ Emmanuel Mutaganzwa ${ }^{5}$, Carl Lombard ${ }^{6}$ and Debra Jackson ${ }^{6,7,8^{*}}$ (D)
}

\begin{abstract}
Background: In 2010, Rwanda adopted ART for prevention of mother to child transmission of HIV from pregnant women living with HIV during pregnancy and breasfeeding period. This study examines rates of mother-to-childtransmission of HIV at 6-10 weeks postpartum and risk factors for mother-to-child transmission of HIV (MTCT) among HIV infected women on ART during pregnancy and breastfeeding.
\end{abstract}

Methods: A cross-sectional survey study was conducted between July 2011-June 2012 among HIV-exposed infants aged 6-10 weeks and their mothers/caregivers. Stratified multi-stage, probability proportional to size and systematic sampling to select a national representative sample of clients. Consenting mothers/caregivers were interviewed on demographic and program interventions. Dry blood spots from HIV-exposed infants were collected for HIV testing using DNA PCR technique. Results are weighted for sample realization. Univariable analysis of socio-demographic and programmatic determinants of early mother-to-child transmission of HIV was conducted. Variables were retained for final multivariable models if they were either at least of marginal significance $(p$-value $<0.10)$ or played a confounding role (the variable had a noticeable impact $>10 \%$ change on the effect estimate).

Results: The study sample was 1639 infants with HIV test results. Twenty-six infants were diagnosed HIV-positive translating to a weighted MTCT estimate of $1.58 \%(95 \% \mathrm{Cl} 1.05-2.37 \%)$. Coverage of most elimination of MTCT (EMTCT) program interventions, was above 80 , and $90.4 \%$ of mother-infant pairs received antiretroviral treatment or prophylaxis. Maternal ART and infant antiretroviral prophylaxis (OR 0.01; 95\% $\mathrm{Cl} 0.001-0.17)$ and maternal age older than 25 years were significantly protective (OR $0.33 ; 95 \% \mathrm{Cl} 0.14-0.78)$. No disclosure of HIV status, not testing for syphilis during pregnancy and preterm birth were significant risk factors for MTCT. Factors suggesting higher sociodemographic status (flush toilet, mother self-employed) were borderline risk factors for MTCT.

Conclusion: ART for all women during pregnancy and breastfeeding was associated with the estimated low MTCT rate of $1.58 \%$. Mothers who did not receive a full package of anti-retroviral therapy according to the Rwanda EMTCT protocol, and young and single mothers were at higher risk of MTCT and should be targeted for support in preventing HIV infection.

Keywords: EMTCT, 6 weeks vertical transmission rate, Operational effectiveness, Sentinel survey, Rwanda, MTCT, EMTCT surveillance, Maternal ART

\footnotetext{
* Correspondence: djackson@unicef.org

${ }^{6}$ Medical Research Council, South Africa (MRC-SA), Francie van Zyl Drive,

Parow 7505, South Africa

7 University of the Western Cape, South Africa (UWC-SA), PB X17 Robert

Sobukwe Road, Bellville 7535, South Africa

Full list of author information is available at the end of the article
}

(c) The Author(s). 2018 Open Access This article is distributed under the terms of the Creative Commons Attribution 4.0 International License (http://creativecommons.org/licenses/by/4.0/), which permits unrestricted use, distribution, and reproduction in any medium, provided you give appropriate credit to the original author(s) and the source, provide a link to the Creative Commons license, and indicate if changes were made. The Creative Commons Public Domain Dedication waiver (http://creativecommons.org/publicdomain/zero/1.0/) applies to the data made available in this article, unless otherwise stated. 


\section{Background}

The global community has committed to the elimination of mother-to-child transmission of HIV (EMTCT) by 2015 and keeping their mothers alive, with targets of < $5 \%$ transmission $(<2 \%$ for early postnatal) and antiretroviral therapy (ART) coverage of at least 90\% [1-4] Measuring impact of EMTCT programs is necessary to track acheivements towards this goal.

Rwanda is located in Eastern Africa, with 10.5 million inhabitants. HIV prevalence in 2017 was estimated at $3.1 \%$ in the general population and $3.8 \%$ among women age 15-49 years. [5] The national EMTCT program started in 2001, and a national EMTCT scale-up plan (2007-2012) articulated a strategy to deliver comprehensive EMTCT interventions within maternal and child health services. [6] The EMTCT program reached $87 \%$ of health facilities by 2012 . All services were generally provided in the same health facility, though not necessarily in the same service point within the facility.

In November 2010, Rwanda EMTCT program adopted antiretroviral treatment (ART) for all pregnant and breastfeeding women (2010 WHO recommendation Option B). [7] Starting April 2012, the EMTCT program extended ART for all pregnant women beyond the breastfeeding period to life-long therapy (also known as Option B+). [7] From 2010 the EMTCT program included infant antiretroviral prophylaxis from birth to age 4-6 weeks. Table 1 compares Option A, B and B+. [7] Chi et.al. [8] reviewed updated literature in 2013 and confirmed the benefits of of all three options, however they note in their conclusion that "To better understand the downstream impact of the Option $\mathrm{B}+$ approach, 'real world' program data are needed and must be carefully evaluated." [8, pg 129] This report provides 'real world' data from the early Rwanda experience using Option B/B+.

This is the first report from a nationally representative study on the early (6-10 postnatal weeks) effectiveness of universal (Option $\mathrm{B}$ or $\mathrm{B}+$ ) perinatal maternal ART on mother-to-child transmission of HIV to measure progress towards EMTCT targets in sub-Saharan Africa. The only other published national early EMTCT effectiveness studies have been from South Africa, [9, 10] which were done when South Africa was using WHO Option A and showed a 6 week transmission of 3.5\% [7]. Other published early effectiveness studies of Option B or B+ have been only regional, not national studies with 10\% MTCT found in Kenya [11] and 6.7\% in Zimbabwe. [12, 13] Finally, one paper has been published on the national 18-month effectiveness of the Zimbabwe EMTCT program during the transition from Option A to Option B. [14] Therefore, this study adds substantially to the current available literature on national effectiveness of Option B or B+ at 6-10 postnatal weeks.

\section{Study objectives}

The study objectives were to: i) to measure rates of early mother-to-child transmission (MTCT) of HIV at 6-weeks postpartum; ii) to estimate coverage of key EMTCT interventions and services (e.g. HIV testing, CD4 cell count testing, infant antiretroviral prophylaxis, counselling on infant feeding); iii) to estimate the association between MTCT rate and ART regimen, maternal background characteristics including CD4 cell count, maternal health care services and maternal and infant health status.

\section{Methods}

A cross-sectional facility-based survey was conducted amongst mother/caregiver-infant pairs attending their 1st Diptheria-Tetanus-Pertussis (DTP1) immunization at six weeks postnatal. This study was conducted in public and faith-based primary health care facilities offering immunizations in all four Rwanda provinces and Kigali City. Health centers with and without an EMTCT program were selected in order to determine the national maternal and child HIV transmission rate. Routine data showed DTP1 coverage was 98.8\%. [15] Facilities with high immunization coverage have been recognized for providing unique opportunities for cost-effectively measuring EMTCT program impact on early MTCT for EMTCT program evaluation. [16, 17] This methodology was first used by Rollins [18] and colleagues, and later was proven to be effective for measuring MTCT in South African. [9], The Rwanda EMTCT Evaluation protocol was adapted from the South African EMTCT

Table 1 Comparison of PMTCT Options A, B and B+ [7, 8]

\begin{tabular}{|c|c|c|c|c|c|c|}
\hline \multirow[t]{2}{*}{ Timing } & \multicolumn{2}{|l|}{ Option A } & \multicolumn{2}{|l|}{ Option B } & \multicolumn{2}{|l|}{ Option B+ } \\
\hline & Mother & Baby & Mother & Baby & Mother & Baby \\
\hline Antepartum & $\begin{array}{l}\text { ZDV from } 14 \text { weeks } \\
\text { onward }\end{array}$ & & $\begin{array}{l}\text { Three drug ARV combination } \\
\text { from } 14 \text { weeks until end of } \\
\text { breastfeeding }\end{array}$ & & $\begin{array}{l}\text { Three drug ARV combination } \\
\text { (from 1st HIV+ test) for life }\end{array}$ & \\
\hline Intrapartum & Single-dose NVP & & & & & \\
\hline Postpartum & 1 week ZDV + 3TC & $\begin{array}{l}\text { NVP for } 6 \text { weeks } \\
\text { or until end of } \\
\text { breastfeeding }\end{array}$ & & $\begin{array}{l}\text { NVP or ZDV until } \\
6 \text { weeks }\end{array}$ & & $\begin{array}{l}\text { NVP or ZDV until } \\
6 \text { weeks }\end{array}$ \\
\hline
\end{tabular}


Evaluation protocol and approved by the National Institute of Statistics of Rwanda and by Rwanda's National Ethics Committee.

\section{Sample}

Participants had to meet the following inclusion criteria: six-to-ten week old infants attending clinic for DPT1 immunization; written informed consent obtained from mother/caregiver; and mother known to be HIV-positive through self reporting, Mother Card or tested HIVpositive during DTP1 visit. For mothers who refused HIV testing, were dead or absent, but mother/guardian consented for the participation of the infant Dry Blood Spot (DBS) ELISA was performed to identify infant HIV exposure. The following were exclusion criteria: infants of mothers known HIV-negative with known HIV-negative partner; infants of mothers who tested HIV-negative to rapid test during the study; severely ill infants needing emergency medical care or urgent referral (e.g. severe vomiting, convulsions, lethargic or unconscious, or severe pneumonia or dehydration) (Fig. 1).

To determine the sample size for each health facility type, expected MTCT rates were calculated based on routine service delivery data for antenatal prevalence and coverage of EMTCT antiretroviral prophylaxis. Estimates of transmission rates for dual-therapy and no treatment are taken from routine service delivery data and previous findings on effectiveness of EMTCT in
Rwanda at 18 months (best available data prior to this study) $[19,20]$.

For EMTCT facilities early (6-10 week) transmission was estimated as $8 \%$, with precision of $2 \%$ required. For Non-EMTCT facilties early transmission was estimated as $25 \%$, with $5 \%$ precision. A design effect of two was used to estimate sample size.

The median number of children immunised in the preceding 12 months from routine service delivery data was used to estimate expected number of children that could be recruited from a facility during the planned study duration. This was averaged for each stratum. The nonresponse rate considered was $5 \%$. This information was used to calculate the number of facilities to be sampled to deliver the planned sample size of 2042 children (1412 in EMTCT Health Facilities and 630 in NonEMTCT Health Facilities).

Sample size required in EMTCT health facilities were allocated proportionally (population proportionate-tosize) across strata (rural versus urban) based on observed 2009 strata immunization totals.

The primary sampling units were public health facilities and faith-based health facilities reportedly administering DTP1 doses in the Rwanda vaccination program report. While other public facilities do administer immunizations, primary level health facilities are the main locations for routine child health services. Data from the 2009 routine service delivery report [21] and the Health Information System database from the Ministry of Health were used to

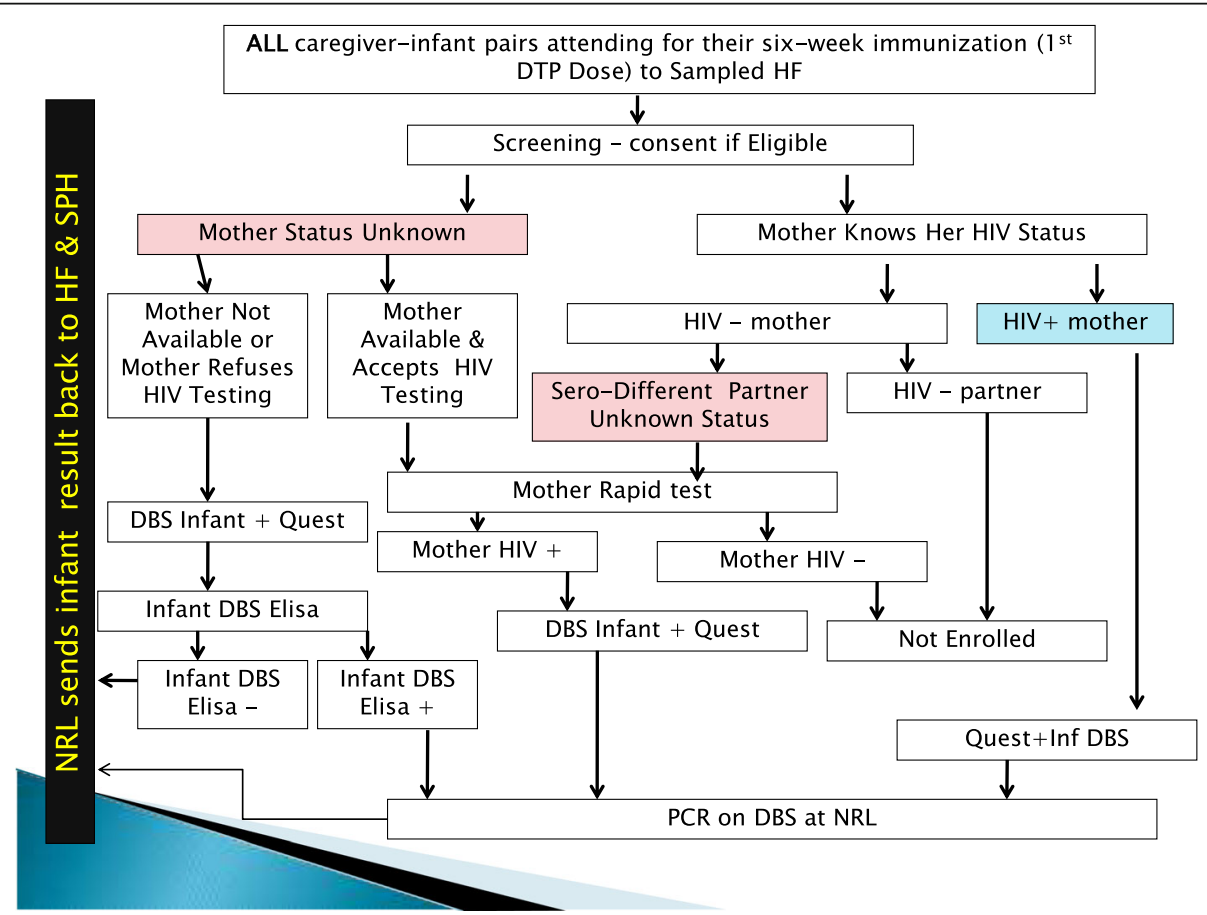

Fig. 1 Testing and Enrollment Algorithm 
obtain the final sampling frame. The study was planned for data collection in 161 out of 412 (39\%) primary health facilities over a period of seven months. Due to the small number of non-EMTCT health facilities available at study initiation $(n=36)$, all non-EMTCT health facilities were sampled.

\section{Data collection}

Health facility nurses providing routine care were trained to recruit mothers/caregivers during immunization days. The nurses introduced the study and signed informed consent was obtained from each eligible mother/caregiver.

Data for the survey were gathered using a questionnaire. Several validated previously field-tested questionnaires were adapted. $[9,18]$ The questionnaire gathered information on maternal age, parity, socio-economic status (living arrangements; income), antenatal care (number of visits, gestation at first booking, HIV testing history; receipt of HIV test results; mother HIV test results; received EMTCT care during pregnancy and delivery; received infant feeding counseling; EMTCT prophylaxis taken (what and when); HIV-related care (CD4 count; on ART); birth information (birth weight; gestation; delivery type) and feeding practices during the past seven days. The questionnaire also documented current infant weight, immunizations, postnatal visits and illness since birth. The questionnaire was translated into Kinyarwanda (Rwanda national language). The questionnaire was tested in EMTCT sites not included in the study sample to test question flow and understanding by participants. Adjustments were made after the pilot (no significant changes necessary).

Trained health care providers collected blood samples. For mothers whose HIV status was unknown by the time of the study, blood samples were taken from consenting mothers and tested at the health center using Rwanda HIV rapid testing algorithm. Dry blood spot (DBS) from HIV-exposed children were tested for HIV using DNA PCR at the National Reference Laboratory of Rwanda. The National Reference Laboratory reported results back to the health facilities and the School of Public Health research team. The quality of the data collection process was checked on daily basis by nursing supervisors, trained laboratory staff and School of Public Health research team. Data entry, cleaning and validation was performed using EPIDATA and analysed using STATA SE 12.1.

\section{Data analysis}

Formal survey analysis included the specification of the sampling stages and the finite number of primary sampling units involved. A weighted analysis was performed for Urban and Rural areas, as well as estimating the national prevalence. The final weights were calculated in 3 phases:

- Calculation of the Weight was based on the inclusion probability of a Health Facility: proportionate to the number of 1st DTP of the Health facility by Stratum

- Calculation of the Weight based on the Sample realization: number of observed (DBS taken and interview done)/number of expected

- Combination (multiply) of the two weights for the calculation of the final weight

- Truncation of the weight: every weight higher than 25 was rounded to 25 .

For non-EMTCT health facilities, a weight of 1 was used since all of them were part of the study. All estimates are reported with $95 \%$ confidence limits.

Basic frequencies and 95\% confidence intervals were used for descriptive analysis. All results are adjusted for clustering effects and weighted as appropriate for proportionate sampling methodology. Denominators for estimates are from those with reported data, missing not included.

Tests for association were carried out using chi-square tests or Fishers Exact tests. All results were adjusted for clustering. Multiple binary logistic regression analysis of predictors of HIV transmission at 6 weeks was conducted. Socio-demographic, health care services, EMTCT services and disease severity variables were examined as potential determinants of MTCT. Variables were retained for final multivariable models if they were either at least of marginal significance $(p$-value $<0.10)$ or played a confounding role (the variable had a noticeable impact $>10 \%$ change on the effect estimate).

\section{Results}

Data collection was from July 2011 to June 2012. The sample realized was 1639 ( $82 \%$ of desired sample size). There was slightly lower sample realisation for Rural EMTCT facilities (892/1191, 75\%), higher than expected sample realization for Urban EMTCT (655/234, 280\%) and substantially lower sample realisation for NonEMTCT sites $(92 / 575,16 \%)$. The sampling frame was adhered to for selected health facilities and allocated time spent was completed according to protocol, but the realization of participants was different from expected. This differential in expected participants experienced per strata was considered due to natural experience of women accessing EMTCT and accounted for during weighting at analysis stage.

A total of 22,305 infants were screened (using a combination of: maternal interview, maternal HIV rapid testing for mothers who reported HIV status unknown, or HIV-negative mother in a discordant couple relationship). 
2066 were identified as HIV-exposed infants and a DBS sample taken. Of these, 1828 met enrollment eligibility criteria, consented to study participation and were interviewed. 189 DBS were rejected by the lab or had indeterminant results, leaving 1639 subjects with both interview questionnaire completed and DNA PCR result available for analysis (Fig. 2).

The average age of the mothers was 29.5 years (SE 0.17) and the majority $(72.5 \%)$ had primary school education. The majority were married (31.3\%) or cohabitating (47.9\%). The main building material of the floor was natural/other (68.1\%), source of drinking water was a public tap (49.2\%), use of a pit latrine (97.5\%), and use of firewood/straw/ dung/other as primary cooking fuel (72.5\%). Almost one in five mothers $(18.9 \%)$ reflected some food insecurity (i.e. ran out of food in the past year) and the majority had fewer assets (61.5\% had 1-3 assets such as a radio, phone, etc.). Just under half of the mothers were employed (47.2\%). The majority $(81.1 \%)$ were multiparas and half $(50.0 \%)$ had planned pregnancies.

Twenty-six infants were diagnosed HIV-positive on DNA PCR. The overall weighted MTCT rate was $1.58 \%$ (95\% CI $1.05-2.38 \%$ ). The rate was $1.28 \%$ (95\% CI $0.71-$ $2.30 \%)$ in rural areas and $2.06 \%$ in urban areas $(95 \% \mathrm{CI}$ $1.17-3.60 \%)$. The difference between the two areas was not statistically significant $(p=0.24)$.

Figure 3 shows results for EMTCT service indicators coverage in HIV-positive mothers and HIV-exposed infants. In all health centers, most of the key EMTCT indicators such as HIV testing, CD4 count, and maternal ART during pregnancy were above $90 \%$. Referral to ART clinic, disclosure of HIV status and infant feeding counseling were below $90 \%$ but above $80 \%$. 97.4\% (95.8-98.4) of infants received antiretroviral prophylaxis. 91.1\% (88.7-93.0) of HIV-positive mothers were on ART during pregnancy and $90.4 \%$ (87.9-92.3) of both mothers and infants received antiretroviral treatment/ prophylaxis per protocol. Exclusive breastfeeding in the last/

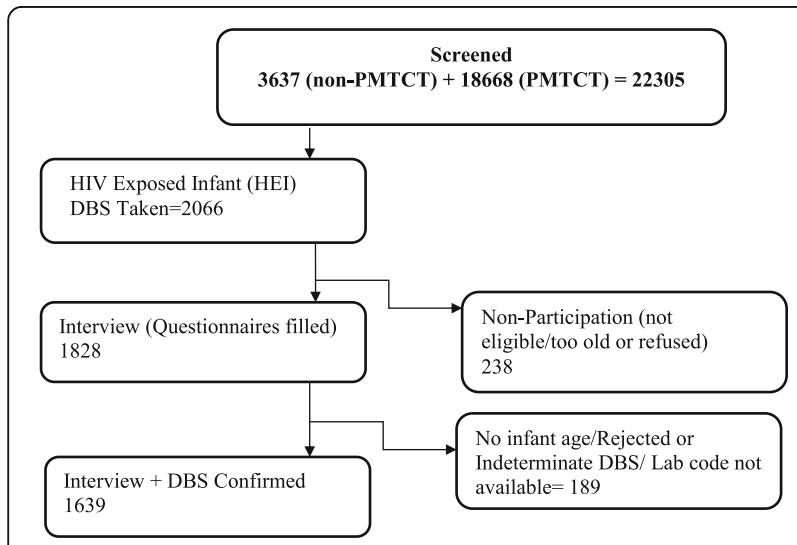

Fig. 2 Study Profile previous 7 days was $88.1 \%$ (85.6-90.3) and coverage of maternal ART at six weeks was $85.6 \%$ (82.9-88.0).

In univariable analyses, socio-demographic factors significantly increasing the risk of MTCT (Table 2) included younger maternal age, marital status and having a flush toilet. Cohabitating was a protective factor reducing the risk of MTCT.

Multiple EMTCT and maternal and child health service factors were significantly associated with MTCT risk (Table 3) reflecting the impact of missed opportunities in the EMTCT cascade even in the context of high EMTCT service coverage. HIV-exposed infants of mothers who were not referred to the ART clinic, or started ART during pregnancy or after delivery compared to starting before pregnancy, were risk factors for MTCT. HIV-exposed infants whose mothers tested HIV-negative or were not tested during pregnancy or not taking ART during pregnancy were at increased risk of MTCT, as was starting infant antiretroviral prophylaxis after $72 \mathrm{~h}$ and incomplete antiretroviral treatment/prophylaxis (lack of anitretrovirals in either mother or baby or both), however these variables did not reach statistical significance $(p<0.05)$. Lack of infant feeding counseling or disclosure of HIV status also increased MTCT risk. Late attendance at antenatal care (3rd trimester) by the mother was a risk factor. Not testing women for syphilis during antenatal care was a risk factor for MTCT, but this variable did not reach statistical significance $(\mathrm{p}<0.05)$.

Three multivariate models were created to assess independent effects on MTCT. Variables in univariable analysis (Tables 2 and 3 ) with a $p$-value $<0.10$ were included in the first two multivariable models. The third model combined significant variables from these intial two models for a final model examining both socio-demographic and EMTCT service factors. A backward step-wise approach was used to generate the final model (Table 4). Due to concerns about statistical power as a result of small number of events $(n=26)$ and potential co-linearity between certain variables (e.g. referral for maternal ART and receipt of maternal ART, measures of maternal and infant antiretroviral treatment/prophylaxis) only the following variables were included in the full model: Maternal HIV testing status; Mother ART clinic referral; Infant Feeding Counseling; HIV Status Disclosure; Late Antenatal Care - 3rd Trimester; Syphilis testing during pregnancy; Delivery attendant; Preterm delivery; Both Mother and Baby getting antiretroviral treatment/prophylaxis; Timing of maternal ART initiation; Timing of infant Nevirapine initiation.

A large number of risk factors remained significant in the final model. Receipt of maternal ART and infant antiretroviral prophylaxis according to Rwanda EMTCT protocol was a highly significant protective factor against MTCT (OR 0.01; 95\%CI 0.001-0.17), while variables suggesting inadequate antiretroviral treatment/prophylaxis 


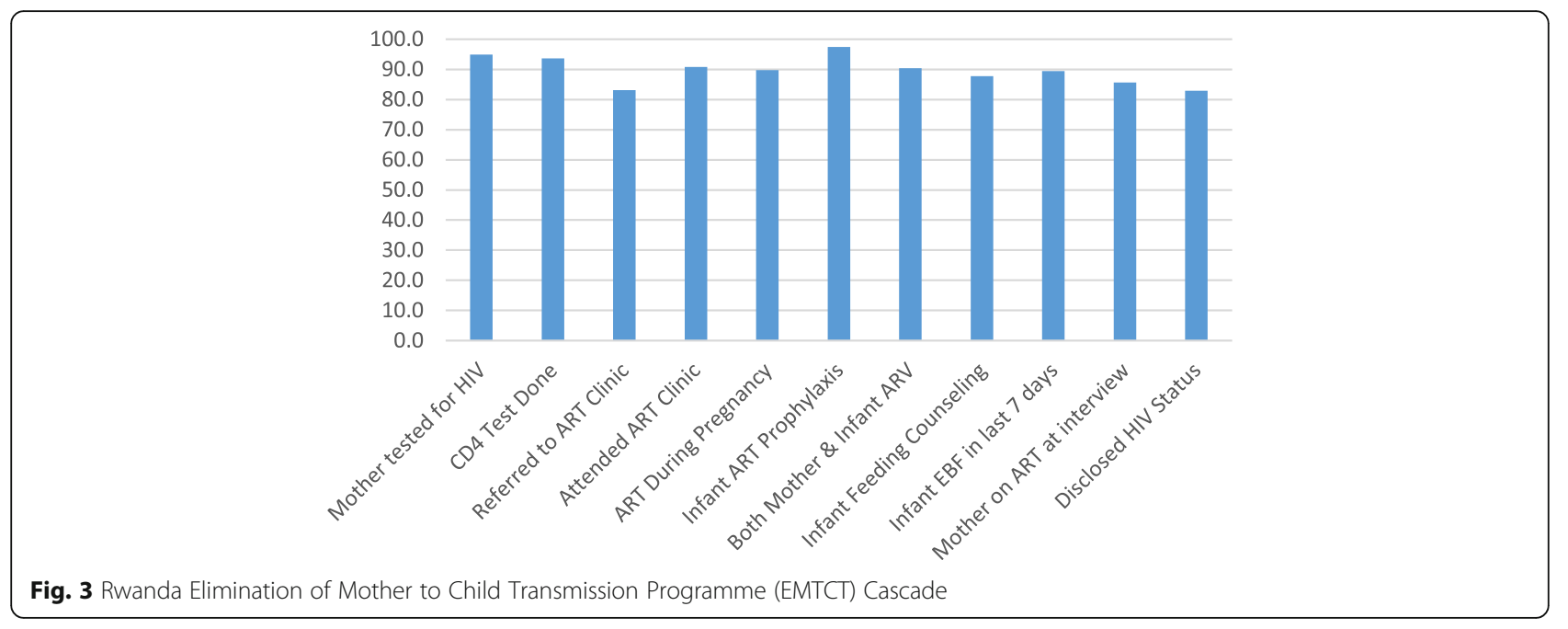

were all significant risk factors (No referral for ART, started of ART after delivery, and start of infant Nevirapine after $72 \mathrm{~h}$ ). Maternal age older than 25 years was protective (OR 0.33; 95\%CI 0.14-0.78). Factors suggesting higher socio-demographic status were risk factors for MTCT (flush toilet, mother self-employed (borderline significant). No disclosure of HIV status, no syphilis testing during pregnancy and preterm birth were also significant risk factors.

\section{Discussion}

The Rwanda rate of early transmission of HIV from mother-to-child of $1.58 \%$ (95\% CI 1.05-2.38\%) showed a reduction from the $2.6 \%$ at 6 weeks reported by routine service delivery data in 2008, though this earlier data from the routine EID program may have reflected selection bias. [21] It also compares favourably to $3.5 \%$ documented in South Africa which was using a combination of dual-therapy and maternal ART (WHO Option A). [9] Compared to regional studies of Option B or B+, this rate compares favorably to $10 \%$ MTCT found in Kenya and $6.7 \%$ in Zimbabwe. [12,13] The Rwanda national target is $2 \%$ at 18 months.

The coverage in the EMTCT Cascade is seen to be high with all indicators above $80 \%$ and many over $90 \%$. (Fig. 3) The primary indicator for EMTCT program coverage is mothers who received ART during pregnancy, this showed a coverage of $91.1 \%$, which is just above the Rwanda 2012 national target of $90 \%$. [6] When both mothers and infants are considered $90.4 \%$ of mothers and babies received the recommended antiretroviral treatment/prophylaxis. Over 90\% coverage of recommended antiretroviral treatment/ prophylaxis during pregnancy is also consistent with UNAIDS targets for global elimination of MTCT, however the drop to $85.6 \%$ at $6-10$ weeks is a concern as it is below the UNAIDS target for ART during breastfeeding of $90 \%$. [10] The coverage figures for mothers and babies combined compare favorably to other studies, such as $65 \%$ in Zimbabwe, [13] 26\% in rural Kenya, [11]. These figures also suggest approximately $10 \%$ missed opportunities for antiretroviral therapy/prophylaxis per Rwandan protocol in mother-baby pairs. These missed opportunities represented a significant risk for increased MTCT (Table 4), which is consistent with other reports in the literature [9-11].

Several socio-demographic factors showed in univariable analysis to increase MTCT risk, however, only flush toilet and mother self-employed remained significant or borderline significant, respectively, in final multivariable analysis (Table 4). This finding suggests that higher socio-economic mothers seem more at risk of MTCT. Bucagu et al. [22] did not find any association of socioeconomic status to MTCT in one health center in Rwanda, however this report was limited in scope and size. While some studies suggest the poor face more barriers to access EMTCT services [23, 24], the findings in this study are consistent with findings from a Nigerian study [25] which found that higher income mothers were less likely to access EMTCT services. Further studies on the relationship of socio-economic status, utilization of EMTCT services and MTCT in Rwanda are needed to allow better targeting of services across populations.

Teen and young mothers $(<25$ years old $)$ also showed a higher risk for mother-to-child transmission in the final multivariable analyses. This result is consistent with the Bucagu study which found a small but nonsignificant increased risk for women age less than 24 [22] and is also consistent with the Nigeria study which found a strong association between teenage mothers and MTCT risk [25]. Younger mothers are theorized to utilize EMTCT services less than older women [25] so this issue is important in the context of the Rwandan EMTCT program. 
Table 2 Univariable Analysis of Infant HIV Infection by Socio-Demographic Factors

\begin{tabular}{|c|c|c|c|c|}
\hline Variable & Answer $(\#)^{*}$ & MTCT \% & $95 \% \mathrm{Cl}$ & $p$-value \\
\hline \multirow[t]{2}{*}{ Infant sex } & Female (826) & 1.8 & $1.1-3.0$ & 0.462 \\
\hline & Male (813) & 1.4 & $0.8-2.3$ & \\
\hline \multirow[t]{3}{*}{ Age of mother } & $35+(399)$ & 1.3 & $0.4-3.8$ & 0.003 \\
\hline & 25-34 (809) & 0.9 & $0.4-1.8$ & \\
\hline & $15-24(360)$ & 3.6 & $2.3-5.7$ & \\
\hline \multirow[t]{3}{*}{ Education of mother } & None (273) & 2.1 & $0.9-4.9$ & 0.308 \\
\hline & Primary (1145) & 1.2 & $0.7-2.1$ & \\
\hline & Secondary+ (183) & 3.5 & $1.3-8.7$ & \\
\hline \multirow[t]{3}{*}{ Marital status of mother } & Married (508) & 2.5 & $1.1-5.5$ & 0.046 \\
\hline & Co-Habitating (797) & 0.6 & $0.2-1.2$ & \\
\hline & Single/Other (324) & 1.9 & $1.1-3.2$ & \\
\hline \multirow[t]{3}{*}{ Main building material of the floor } & Natural/Other (1629) & 2.7 & $1.4-5.1$ & 0.334 \\
\hline & Rudimentary (152) & 1.2 & $0.2-5.8$ & \\
\hline & Finished (383) & 1.3 & $0.7-2.2$ & \\
\hline \multirow[t]{4}{*}{ Main source of drinking water } & Tap in House/Yard (154) & 2.3 & $1.0-5.2$ & 0.696 \\
\hline & Public Tap (859) & 1.6 & $0.9-2.8$ & \\
\hline & Well (covered or uncovered) (469) & 1.1 & $0.4-3.1$ & \\
\hline & Spring/River/Other (146) & 2.3 & $0.8-6.6$ & \\
\hline \multirow[t]{3}{*}{ Type of toilet } & Flush (16) & 10.2 & $2.2-36.6$ & 0.004 \\
\hline & Pit Latrine (1580) & 1.5 & $1.0-2.4$ & \\
\hline & None/Bush/Other (31) & 0 & - & \\
\hline \multirow[t]{2}{*}{ Main source of cooking fuel } & Firewood/Dung/ Other (1133) & 1.2 & $0.7-2.1$ & 0.071 \\
\hline & Elec/Gas/Kerosene/ Charcoal (497) & 2.7 & $1.6-4.5$ & \\
\hline \multirow[t]{2}{*}{ Depletion of food in past 12 months } & Never ran out of food (1320) & 1.9 & $0.8-4.3$ & 0.717 \\
\hline & Ran out of food (299) & 1.5 & $0.9-2.5$ & \\
\hline \multirow[t]{2}{*}{ Number of Pregnancies } & One (309) & 2.3 & $1.2-4.4$ & 0.312 \\
\hline & 2 or more (1295) & 1.4 & $0.9-2.4$ & \\
\hline \multirow[t]{2}{*}{ Planned Pregnancy } & Not Planned (767) & 1.2 & $0.7-2.1$ & 0.079 \\
\hline & Planned (794) & 2.0 & $1.2-3.3$ & \\
\hline \multirow[t]{3}{*}{ Religion } & Catholic (662) & 1.9 & $1.0-3.4$ & 0.518 \\
\hline & Other Christian (739) & 1.3 & $0.7-2.3$ & \\
\hline & Other Religion (223) & 1.9 & $1.0-3.5$ & \\
\hline \multirow[t]{2}{*}{ Rural or Urban } & Rural (984) & 1.3 & $0.7-2.3$ & 0.268 \\
\hline & Urban (655) & 2.1 & $1.2-3.6$ & \\
\hline \multirow[t]{3}{*}{ Source of income (can indicate multiple sources) } & Self-Employed (744) & 2.2 & $1.3-3.8$ & 0.115 \\
\hline & Other Source (970) & 0.9 & $0.5-1.6$ & \\
\hline & None (96) & 1.5 & $0.3-7.3$ & \\
\hline \multirow{3}{*}{$\begin{array}{l}\text { Composite Asset Indicator (Electricity, Radio, TV, Phone, } \\
\text { Refrigerator, Bicycle, Motorcycle/Scooter, Car) }\end{array}$} & 0 assets (507) & 1.3 & $0.6-2.9$ & 0.323 \\
\hline & $1-2-3$ assets $(1000)$ & 1.5 & $0.8-2.7$ & \\
\hline & $4-5-6$ assets (126) & 3.5 & $1.7-7.5$ & \\
\hline
\end{tabular}

*Totals may not add to $100 \%$ due to missing

Lack of disclosure of HIV status showed an almost 7 -fold increase in MTCT in the multivariable analysis. More than half (53-65\%) of people in the Rwanda DHS indicated an accepting attitude towards persons with HIV/AIDS, [15] and a study of Rwandans with HIV showed limited perceived discrimination [26]. However, 
Table 3 Univariable Analysis of Infant HIV Infection by EMTCT Service and Other Health System \& Maternal/Infant indicators

\begin{tabular}{|c|c|c|c|c|c|c|c|c|c|}
\hline \multirow{2}{*}{$\frac{\text { Variable }}{\text { EMTCT Site }}$} & \multirow{2}{*}{$\frac{\text { Answer }(\#)^{*}}{\text { Yes (1547) }}$} & \multirow{2}{*}{$\frac{\text { MTCT \% }}{1.6}$} & \multirow{2}{*}{$\begin{array}{l}95 \% \mathrm{Cl} \\
1.1-2.5\end{array}$} & \multirow{2}{*}{$\frac{p \text {-value }}{0.097}$} & \multicolumn{5}{|l|}{ (Continued) } \\
\hline & & & & & \multirow{3}{*}{$\begin{array}{l}\text { Variable } \\
\text { Infant } \\
\text { Cotrimoxazole }\end{array}$} & Answer $(\#)^{*}$ & MTCT \% & $95 \% \mathrm{Cl}$ & $p$-value \\
\hline & No (92) & 0.7 & $0.2-2.4$ & & & Yes (639) & 1.1 & $0.5-2.7$ & 0.217 \\
\hline \multirow{3}{*}{$\begin{array}{l}\text { HIV Test } \\
\text { Results } \\
\text { written } \\
\text { on Card }\end{array}$} & Yes (1516) & 1.6 & $1.0-2.5$ & \multirow[t]{3}{*}{0.0504} & & No (965) & 2.0 & $1.3-3.2$ & \\
\hline & \multirow[t]{2}{*}{ No (81) } & \multirow[t]{2}{*}{0.5} & \multirow[t]{2}{*}{$0.1-1.9$} & & \multirow{3}{*}{$\begin{array}{l}\text { Infant } \\
\text { Feeding } \\
\text { Counselling } \\
\text { received }\end{array}$} & Yes (1420) & 1.1 & $0.6-2.0$ & 0.024 \\
\hline & & & & & & No (194) & 3.6 & $2.1-6.1$ & \\
\hline \multirow{4}{*}{$\begin{array}{l}\text { Mother HIV } \\
\text { testing during } \\
\text { pregnancy (in } \\
\text { Negative or } \\
\text { Unknown at } \\
\text { beginning of } \\
\text { pregnancy) }\end{array}$} & Yes (1615) & 1.6 & $1.0-2.4$ & \multirow[t]{4}{*}{0.6220} & & & & & \\
\hline & \multirow[t]{2}{*}{ No (24) } & \multirow[t]{2}{*}{2.4} & \multirow[t]{2}{*}{$0.6-10.0$} & & \multirow{2}{*}{$\begin{array}{l}\text { Infant } \\
\text { Feeding } \\
\text { exclusive } \\
\text { breastfeeding } \\
\text { in last } 24 \mathrm{~h}\end{array}$} & Yes (1439) & 1.5 & $0.9-2.3$ & 0.399 \\
\hline & & & & & & No (196) & 2.4 & $1.0-5.7$ & \\
\hline & \multirow{3}{*}{$\begin{array}{l}\text { Tested HIV+ } \\
\text { during } \\
\text { pregnancy } \\
(1280)\end{array}$} & \multirow{3}{*}{1.2} & \multirow{3}{*}{$0.7-2.1$} & & \multirow[t]{2}{*}{ Any Breastfeeding } & Yes (1429) & 1.5 & $1.0-2.4$ & 0.535 \\
\hline \multirow{7}{*}{$\begin{array}{l}\text { Mother HIV } \\
\text { status known } \\
\text { during } \\
\text { pregnancy }\end{array}$} & & & & \multirow{7}{*}{0.051} & & No (210) & 2.1 & $0.9-5.1$ & \\
\hline & & & & & Disclosed status & Yes (1340) & 1.1 & $0.7-1.9$ & 0.006 \\
\hline & \multirow{3}{*}{$\begin{array}{l}\text { Tested HIV } \\
\text { Negative } \\
\text { during pregnancy } \\
\text { (162) }\end{array}$} & 3.5 & $1.7-7.0$ & & & Nov (252) & 4.1 & $2.4-6.8$ & \\
\hline & & & & & Perceived & Yes (212) & 2.7 & $1.2-6.0$ & 0.255 \\
\hline & & & & & Discrımınatı & No (1372) & 1.5 & $0.9-2.3$ & \\
\hline & Not tested during & 2.7 & $1.4-5.1$ & & Antenatal Care & 0 visits (17) & 11.3 & $3.5-30.9$ & 0.130 \\
\hline & pregnancy (177) & & & & & 1 or more & 1.5 & $1.0-2.3$ & \\
\hline Mother CD4 & CD4 done (1505) & 1.6 & $1.0-2.4$ & 0.432 & & & & & \\
\hline Count done & CD4 not done (92) & 2.7 & 1.07 .4 & & $\begin{array}{l}\text { Gestational } \\
\text { Age started }\end{array}$ & $\begin{array}{l}<27 \text { Weeks } \\
(1093)\end{array}$ & 1.0 & $0.5-2.0$ & 0.049 \\
\hline Mother referred & Yes referred (1316) & 1.1 & $0.6-2.0$ & 0.034 & antenatal care & $>=27$ Weeks & 2.7 & $1.5-4.6$ & \\
\hline & Not referred (242) & 3.2 & $1.9-5.6$ & & & $(546)$ & & & \\
\hline CD4 level & $>350(275)$ & 2.2 & $1.1-4.5$ & 0.328 & Syphilis Screen & Yes (1264) & 1.4 & $0.9-2.3$ & 0.062 \\
\hline & $<=350(1075)$ & 1.4 & $0.7-2.5$ & & & No (237) & 3.0 & $1.8-5.2$ & \\
\hline Mother visited & Yes (1467) & 1.6 & $1.1-2.5$ & 0.637 & Tuberculosis & Yes (602) & 1.9 & $1.0-3.6$ & 0.458 \\
\hline & No (107) & 1.2 & $0.3-4.6$ & & $\begin{array}{l}\text { Screen durıng } \\
\text { pregnancy }\end{array}$ & No (952) & 1.4 & $0.8-2.4$ & \\
\hline Maternal took & Yes (1474) & 1.3 & $0.8-2.1$ & 0.051 & Place of Delivery & Facility (1525) & 1.5 & $0.9-2.2$ & 0.257 \\
\hline $\begin{array}{l}\text { ARI/ARV } \\
\text { during }\end{array}$ & No (120) & 4.9 & $2.4-9.8$ & & & Home/Other (98) & 3.5 & $1.3-9.1$ & \\
\hline pregnancy & & & & & Method & Vaginal (1343) & 1.4 & $0.9-2.2$ & 0.897 \\
\hline $\begin{array}{l}\text { Mother timing } \\
\text { of initiation }\end{array}$ & $\begin{array}{l}\text { Prior to } \\
\text { pregnancy (637) }\end{array}$ & 0.4 & $0.2-0.9$ & 0.012 & of Delivery & $\begin{array}{l}\text { Caesarean } \\
\text { Section (237) }\end{array}$ & 1.5 & $0.6-4.0$ & \\
\hline & $\begin{array}{l}\text { During } \\
\text { Pregnancy (686) }\end{array}$ & 1.9 & $1.1-3.4$ & & Delivered by & Doctor (310) & 1.4 & $0.6-3.3$ & 0.449 \\
\hline & After Delivery (44) & 8.6 & $2.5-26.2$ & & & $\begin{array}{l}\text { Midwife/ } \\
\text { Nurse (1217) }\end{array}$ & 1.4 & $0.9-2.4$ & \\
\hline $\begin{array}{l}\text { Infant ARV } \\
\text { Prophylaxis }\end{array}$ & $\begin{array}{l}\text { Nevirapine } \\
\text { within } 72 \text { h (1149) }\end{array}$ & 1.2 & $1.0-2.4$ & 0.062 & & $\begin{array}{l}\text { Traditional } \\
\text { Birth Attendant/ }\end{array}$ & 4.2 & $1.6-10.6$ & \\
\hline & Nevirapine not & 2.7 & $1.6-4.5$ & & & Other (80) & & & \\
\hline & $\begin{array}{l}\text { within } 12 \text { hours } \\
\text { but within } 6\end{array}$ & & & & Low Birth & Yes (85) & 2.2 & $1.0-4.9$ & 0.467 \\
\hline & weeks/no (430) & & & & & No (1533) & 1.5 & $1.0-2.4$ & \\
\hline Mother-Baby & Mother \& Baby & 1.3 & $0.8-2.2$ & 0.056 & Preterm & Yes (41) & 3.5 & $1.3-9.4$ & 0.349 \\
\hline & & & & & & No (1598) & 1.5 & $1.0-2.4$ & \\
\hline
\end{tabular}

Not MotherBaby ART/ARV (either mother or baby or both no treatment) (128)
Table 3 Univariable Analysis of Infant HIV Infection by EMTCT Service and Other Health System \& Maternal/Infant indicators

*Totals may not add to $100 \%$ due to missing

lack of disclosure and stigma may impact on both treatment adherence and safe infant feeding. Stigma and disclosure to family and friends of HIV status have 
Table 4 Final Multivariable Model examining socio-demographic and EMTCT service variables as predictors of MTCT

\begin{tabular}{|c|c|c|c|c|c|c|}
\hline Variables & Odds ratio & Std Err. & $\mathrm{t}$ & $\operatorname{Pr}(T>t)$ & $95 \%$ C & lence Interval \\
\hline & 5.53 & 2.53 & 3.74 & $<0.001$ & 2.24 & 13.70 \\
\hline Mother timing of initiation of ART during pregnancy (Ref: $1=$ prior to pregnancy) & 2.03 & 1.18 & 1.22 & 0.226 & 0.64 & 6.44 \\
\hline Mother timing of initiation of ART after delivery (Ref: $1=$ prior to pregnancy) & 236.54 & 267.37 & 4,84 & $<0.001$ & 25.26 & 2213.05 \\
\hline No Disclosure (Ref: Disclosure) & 6.19 & 1.87 & 6.05 & $<0.001$ & 3.41 & 11.24 \\
\hline Gestational Age started antenatal care $>=27$ weeks (Ref: $<27$ weeks) & 1.65 & 0.73 & 1.12 & 0.264 & 0.68 & 3.97 \\
\hline No Syphilis Screen during pregnancy (Ref: Yes) & 2.87 & 0.90 & 3.35 & 0.001 & 1.54 & 5.35 \\
\hline Full Term (Ref: Preterm) & 0.24 & 0.09 & -3.95 & $<0.001$ & 0.12 & 0.50 \\
\hline Infant ARV Prophylaxis Initiation within 6 weeks (Ref:Nevirapine within 72 h) & 5.01 & 1.99 & 4.05 & $<0.001$ & 2.28 & 11.02 \\
\hline Both Mother \& Baby got ART/ARV (Ref: either mother or baby or both no ART/ARV) & 0.01 & 0.18 & -3.40 & 0.001 & 0.001 & 0.17 \\
\hline Mother age $>25$ (Ref: $<=25$ years old) & 0.33 & 0.13 & -2.54 & 0.012 & 0.14 & 0.78 \\
\hline Source of income Self-employed (Ref: None) & 2.78 & 1.62 & 1.75 & 0.082 & 0.88 & 8.82 \\
\hline Type of toilet Pit (Ref: Flush) & 0.12 & 0.07 & -3.92 & $<0.001$ & 0.04 & 0.35 \\
\hline
\end{tabular}

consistently been seen to impact EMTCT care and treatment adherence in the literature [22, 26-29].

Two antenatal care variables were significant risk factors for MTCT, antenatal care started after 27 weeks gestation and no maternal syphilis test during pregnancy. Not having a syphilis test remained significant in the final model. This association was also seen in a South African cohort study, which theorized that syphilis testing may be a marker for quality of antenatal care [30]. More recent policy analyses suggest the need for integration across HIV and Syphillis elimination programs to improve antenatal quality of care [31]. Preterm birth was a risk factor for MTCT which is consistent with the literature [30].

Limitations of the current design must be recognized. The data were facility-based using infants presenting for immunization. In their 2012 publication 'A short guide on methods: measuring the impact of national EMTCT programmes: towards the elimination of new HIV infections in children by 2015 and keeping their mothers alive, WHO recognizes this methodology as one of several available to assess EMTCT impact. [17] This document notes the following pros and cons for this method: "in settings with high immunization coverage, real time data can be captured to inform population-level transmission and early infant HIV infection; relatively quick to undertake and can be repeated to provide trend data, especially if a modest amount of additional data is collected at the same time; also provides results for infants of mothers who did not attend antenatal clinic or receive EMTCT care; however this design misses children who have died before immunization" [17,pg9].

In Rwanda the 6 week immunization visit has high attendance nationally (98.8\%) meeting the condition for high immunisaiton coverage as suggested by WHO. In addition, the socio-demographic factors in this study were similar to those in the Rwanda DHS completed the year prior to the study. [15] Identification and referral of eligible infants to the clinic was also done during the immunization outreach strategy program in villages to maximize the chance of having all eligible infants. Infants who did not come for immunization, had severe illness or had already died by 6 weeks of age were not included in the sample suggesting a possible underestimation of prevalence. Also, there were differences in the expected sample size per sampling strata (e.g. urban/ rural and EMTCT/Non-EMTCT). These differentials may have existed as there were fewer Non-EMTCT sites due to rapid EMTCT program scale-up, and clients may have traveled to urban areas and EMTCT clinic sites in expection of more comprehensive services. These differences across strata were accounted for by weighting during statistical analyses. There is always potential for recall bias, however the relatively short recall period of 6 weeks minimizes this potential bias. Social desirability bias and fear of disclosure and stigma may cause mothers to either over or under-report participation in the EMTCT program. Confidentiality was assured and discussed as part of the informed consent process and a private place was secured for conducting interviews. In addition, data collectors were routine clinic nurses who had full access to maternal and newborn records to identify possible HIV-exposed infants. Established sensitivity and specificity of the HIV testing were operational, but should have been minimized through proper handling of specimens and assurance of laboratory quality control. The study did not include a measure of daily adherence to ART only regimen. In addition, national averages could hide subnational disparities not addressed in this study and suggest a need for further investigations on equity in the EMTCT program. 


\section{Conclusions}

The low rate of MTCT of $1.58 \%$ achieved in Rwanda is a clear indication that new HIV infections in children can reach elimination targets. To reduce the the MTCT rate futher, the program must begin to address existing missed opportunities, particularly with regard to coverage of maternal ART and infant antiretroviral prophylaxis. Integration of EMTCT within the maternal and child health care platform [32], enhanced early treatment with ART and retention in care, starting antenatal care early and continuing antenatal care are some of the strategies to minimize the risks of missed opportunities. In addition, young, single mothers appear to be at higher risk suggesting the need for targeting this population.

\section{Abbreviations}

ART: antiretroviral therapy; ARV: antiretroviral (prophylaxis); CD4: cluster of differentiation 4, a type of lymphocite; DBS: dry blood spot; DNA PCR: deoxyribonucleic acid polymerase chain reaction; DPT1: diptheria, polio and tetanus vaccine, given as first dose; EMTCT: elimination of mother-to-child transmission of HIV; HIV: human immunodefieciency virus; MTCT: mother-to-child transmission of HIV, also know as vertical transmission of HIV; UNAIDS: The Joint United Nations Program on HIV/ AIDS; WHO: World Health Organization

\section{Acknowledgements}

The authors wish to thank RBC/IHDPC and National Research Laboratory for their support of this project, and we would also like to thank the health facility staff who assisted with data collection, and the mothers and infants who participated in the study.

\section{Funding}

This study was funded by UNICEF Rwanda and also supported by the Rwanda Biomedical Center/Institute of HIV, Disease Prevention and Control, Rwanda Ministry of Health and Rwanda National Research Laboratory. Individuals from these supporting institutions were involved in study design (PM, LT, FM, VM, SN, MR, Al, ME, DJ), patient recruitment and data collection (Rwanda Ministry of Health employed clinic nurses). The study was also supported by the South Africa National Research Foundation (DJ), which supported travel for Rwandan researchers to travel to South Africa for consultation with South African coauthors (particularly for statistical analysis) and DJ to Rwanda for study analysis and writing.

\section{Availability of data and materials}

Supporting data can be requested from Rwanda Government from the first author(mu_placy@yahoo.fr).

\section{Authors' contributions}

PM and AL were the study principal investigators. DJ acted as a technical consultant and wrote first draft of the manuscript and is corresponding author. All authors (PM, AL, AU, JH, LT, FM, VM, SN, MR, Al, EM, CL, DJ) were members of the steering committee which developed the initial study protocol, approved the analysis plan and contributed to writing and editing of the manuscript. LT and FM coordinated the steering committee communications and acted as study co-principal investigators. Co-authors from the Rwanda Biomedical Council (PM, VM, SN, MR, Al) managed aspects of the study implementation at study sites. The University of Rwanda Team ( $A L, A U$, $\mathrm{JH}$ ) in collaboration with Rwanda Biomedical Council (PM, VM, SN, MR, $\mathrm{Al}$ ) conducted the training of data collection team (nurses) and EM the training on the lab component of the study. $\mathrm{AL}, \mathrm{AU}, \mathrm{JH}$ and $\mathrm{PM}$ supervised data collection, data entry and data cleaning. EM supervised all laboratory analyses. $\mathrm{AL}, \mathrm{CL}, \mathrm{AU}$ and DJ conducted data analysis. All authors had access to study data and approved the final manuscript for submission.

\section{Ethics approval and consent to participate}

This research involved human subjects was performed in accordance with the Declaration of Helsinki. The study was approved by the National Institute of Statistics of Rwanda and by Rwanda National Ethics Committee. All participant mothers/caregivers signed a written informed consent and were assured of no repercussions should they wish not to participate or to withdraw at any time for any reason.

\section{Consent for publication}

Not Applicable.

\section{Competing interests}

The authors declare that they have no competing interest.

\section{Publisher's Note}

Springer Nature remains neutral with regard to jurisdictional claims in published maps and institutional affiliations.

\section{Author details}

${ }^{1}$ Rwanda Biomedical Center/Institute of HIV, Disease Prevention and Control (RBC/IHDPC), KN 3 Road, Kigali, Rwanda. ${ }^{2}$ School of Public Health, College of Medicine and Health Sciences, National University of Rwanda

(SPH-CMHS-UR), Kigali 5229, Rwanda. ${ }^{3}$ UNICEF, Western and Central Africa Regional Office, Dakar, Senegal. ${ }^{4}$ UNICEF Rwanda, Boulevard de I'Umunganda, Kacyiru, Kigali, Rwanda. ${ }^{5}$ National Reference Laboratory Rwanda, KN 3 Road, Kigali, Rwanda. ${ }^{6}$ Medical Research Council, South Africa (MRC-SA), Francie van Zyl Drive, Parow 7505, South Africa. ${ }^{7}$ University of the Western Cape, South Africa (UWC-SA), PB X17 Robert Sobukwe Road, Bellville 7535, South Africa. ${ }^{8}$ UNICEF, New York, 3 UN Plaza, New York, NY 10017, USA.

Received: 20 February 2018 Accepted: 26 October 2018

Published online: 12 November 2018

\section{References}

1. WHO/UNAIDS/UNICEF,. Global update on HIV treatment 2013: Results, impact and opportunities. Geneva: World Health Organization, 2013. http://www.unaids.org/sites/default/files/media_asset/20130630_ treatment_report_en_0.pdf. [Accessed 16 July 2018].

2. WHO and UNAIDS and UNICEF, Global HIV/AIDS response: Epidemic update and health sector progress towards universal access: progress report 2011. Geneva: WHO 2011. http://apps.who.int/iris/bitstream/handle/10665/44787/ 9789241502986_eng.pdf;jsessionid=B50DEBA3FAOFDE916F5879E498D3CDCF? sequence $=1$. [Accessed 16 July 2018].

3. UNAIDS. Global plan towards the elimination of new HIV infections among children by 2015 and keeping their mothers alive 2011. Geneva: UNAIDS; 2011. http://www.unaids.org/en/media/unaids/contentassets/documents/ unaidspublication/2011/20110609_JC2137_Global-Plan-Elimination-HIVChildren_en.pdf. [Accessed 16 July 2018].

4. WHO. Global monitoring framework and strategy for the Global Plan towards the elimination of new HIV infections among children by 2015 and keeping their mothers alive (eMTCT). Geneva: WHO 2012. http://apps.who. int/iris/bitstream/10665/75341/1/9789241504270_eng.pdf?ua=1. [Accessed 16 July 2018].

5. UNAIDS Country fact sheets Rwanda 2016. http://www.unaids.org/en/ regionscountries/countries/rwanda. [Accessed 16 July 2018].

6. National AIDS Control Commission (CNLS) National Strategic Plan on HIV \& AIDS 2009-2012. Kigali 2009. http://www.ilo.org/wcmsp5/groups/public/ \%2D\%2D-ed_protect/\%2D\%2D-protrav/\%2D\%2D-ilo_aids/documents/ legaldocument/wcms_127584.pdf. [Accessed 17 July 2018].

7. World Health Organization. Consolidated guidelines on the use of antiretroviral drugs for treating and preventing HIV infection: Recommendations for a public health approach. Geneva: WHO 2013. http://www.who.int/hiv/pub/ guidelines/arv2013/en/. [Accessed 16 July 2018].

8. Chi BH, Stringer JSA, Moodley D. Antiretroviral drug regimens to prevent mother-to-child transmission of HIV: a review of scientific, program, and policy advances for sub-Saharan Africa. Curr HIV/AIDS Rep. 2013;10:124-33. https://doi.org/10.1007/s11904-013-0154-z.

9. Goga AE, Dinh TH, Jackson D, Lombard C, Delaney K, Puren A, et al. First population-level effectiveness evaluation of a national programme to prevent HIV transmission from mother to child. South Africa J Epidemiol Community Health. 2014;0:1-9. https://doi.org/10.1136/jech-2014-204535.

10. Goga AE, Dinh TH, Jackson DJ, Lombard CJ, Puren A, Sherman G, et al. Population-level effectiveness of PMTCT option a on early mother-tochild (MTCT) transmission of HIV in South Africa: implications for 
eliminating MTCT. J Glob Health. 2016;6(2):020405. https://doi.org/10. 7189/jogh.06.020405.

11. Azcoaga-Lorenzo A, Ferreyra C, Alvarez A, Palma PP, Velilla E, del Amo J. (2011) effectiveness of a PMTCT programme in rural Western Kenya. AIDS Care. 2011;23:274-80. https://doi.org/10.1080/09540121.2010.507750.

12. Ngemu EK, Khayeka-Wandabwa C, Kweka EJ, Choge JK, Anino E, OyooOkoth E. Effectiveness of option B highly active antiretroviral therapy (HAART) prevention of mother-to-child transmission (PMTCT) in pregnant HIV women. BMC Research Notes. 2014;7:52 http://www.biomedcentral. com/1756-0500/7/52. [Accessed 7 July 2018].

13. McCoy SI, Fahey C, Buzdugan R, Mushavi A, Mahomva A, Padian NS, Cowan FM. Targeting elimination of mother-to-child HIV transmission efforts using geospatial analysis of mother-to-child HIV transmission in Zimbabwe. AIDS. 2016;30(11):1829-37. https://doi.org/10.1097/QAD.0000000000001127.

14. Dinh TH, Mushavi A, Shiraishi RW, Tippett Barr B, Balachandra S, Shambira G, et al. Findings from an 18-month prospective cohort of a nationally representative sample of mother-infant pairs during the transition from option a to option B+ in Zimbabwe. Clin Infect Dis. 2018;66(4):576-85. https://doi.org/10.1093/cid/cix820.

15. National Institute of Statistics of Rwanda (NISR) [Rwanda], Ministry of Health (MOH) [Rwanda], and ICF International. Rwanda demographic and health survey 2010. Calverton: NISR, MOH, and ICF International; 2012. https:// dhsprogram.com/pubs/pdf/FR259/FR259.pdf. [Accessed 16 July 2018].

16. UNICEF/WHO/UNAIDS. Consultative Meeting on Evaluating The Impact Of Prevention of Mother-To-Child Transmission of HIV (EMTCT) Services In LowAnd Middle-Income Countries In Averting New HIV Infections In Children And Improving Child Survival. 12-13 February, 2009 Vanderbilt University school of medicine Nashville, Tennessee, USA. New York: UNICEF. 2010. https:/www.unicef.org/aids/files/Final_Vanderbilt_Meeting_Report_ March30Resized6.pdf. [Accessed 16 July 2018].

17. WHO. A short guide on methods: measuring the impact of national EMTCT programmes: towards the elimination of new HIV infections among children by 2015 and keeping their mothers alive. Geneva: WHO 2012. http://apps.who.int/iris/bitstream/handle/10665/75478/9789241504362_eng. pdf;jsessionid $=251$ A30E133620CB5CFA09C8B2E63F77E? sequence $=1$. [Accessed 16 July 2018].

18. Rollins NC, Little K, Mzoloa C, Newell M-L. Surveillance of mother-to-child transmission prevention programmes at immunization clinics: the case for universal screening. AIDS. 2007;21:1341-7.

19. Mugwaneza P, Umutoni N, Ruton H, Rukundo A, Lyambabje A, de Dieu BJ, et al. Under-two child mortality according to maternal HIV status in Rwanda: assessing outcomes within the national EMTCT program. Pan Afr Med J. 2011;9:37.

20. Ruton H, Mugwaneza P, Shema N, Lyambabaje A, de Dieu BJ, Tsague L, et al. HIV-free survival among nine- to 24-month-old children born to HIVpositive mothers in the Rwandan national EMTCT program: a communitybased household survey. J Int AIDS Soc. 2012;15:4

21. Republic of Rwanda Ministry of Health. Rwanda Ministry of Health Annual Statistical Booklet 2008. Kigali: Rwanda Ministry of Health. p. 2009. http:// www.statistics.gov.rw/file/1313/download?token=6b-fpQWo. [Accessed 30 Oct 2018].

22. Bucagu M, de Dieu Bizimana J, Muganda J, Humblet CP. Socio-economic, clinical and biologic risk factors for mother-to child transmission of HIV-1 in Muhima health Centre (Rwanda): a prospective cohort study. Archives Public Health. 2013;71:4.

23. Hiarlaithe MO, Grede N, de Pee S, Bloem M. Economic and social factors are some of the most common barriers preventing women from accessing maternal and newborn child health (MNCH) and prevention of mother-tochild transmission (EMTCT) services: a literature review. AIDS Behav. 2014; 18(Suppl 5):S516-30. https://doi.org/10.1007/s10461-014-0756-5.24.

24. Colvin M, Chopra M, Doherty T, Jackson D, Levin J, Willumsen J, et al. Operational effectiveness of single-dose Nevirapine in preventing motherto-child transmission of HIV. Bull World Health Organ. 2007;85(6):466-73. https://doi.org/10.2471/BLT.06.033639.

25. Amoran OE, Salami OF, Oluwole FA. A comparative analysis of teenagers and older pregnant women in the utilization of prevention of mother to child transmission [EMTCT] services in Western Nigeria. BMC Int Health Hum Rights. 2012;12:13. https://doi.org/10.1186/1472-698x-12-13.

26. Nyiramanyana C, Gumuyire J, Ruturwa D, Pegurri E. People living with HIV stigma index: Rwandan stigma and discrimination survey report. Association of Vulnerable Widows Infected and Affected by HIV \&
AIDS and UNAIDS: Kigali; 2009. http://www.stigmaindex.org/sites/ default/files/reports/Rwanda\%20People\%20Living\%20with\%20HIV\% 20Stigma\%20Index\%20_Rwanda\%20survey\%20report-FINALJuly\%202009.pdf. [Accessed 16 July 2018].

27. Medley A, Garcia-Moreno C, McGill S, Maman S. Rates, barriers and outcomes of HIV serostatus disclosure among women in developing countries: implications for prevention of mother-to-child transmission programmes. Bull World Health Organ. 2004;82(4):299-307 PMCID: PMC2585956.

28. Nuwagaba-Biribonwoha H, Mayon-White RT, Okong P, Carpenter LM. Challenges faced by health workers in implementing the prevention of mother-to-child HIV transmission (EMTCT) programme in Uganda. J Public Health. 2007;29(3):269-74. https://doi.org/10.1093/pubmed/fdm025.

29. Stirratt MJ, Remien RH, Smith A, Copeland OQ, Dolezal C, Krieger D. The role of HIV Serostatus disclosure in antiretroviral medication adherence. AIDS Behav. 2006;10(5):483-93. https://doi.org/10.1007/s10461-006-9106-6.

30. Jackson D, Chopra M, Doherty T, Colvin M, Levin J, Willumsen J, et al. Operational effectiveness and 36 week HIV-free survival in the south African programme to prevent mother-to-child transmission of HIV-1. AIDS. 2007;21:509-16.

31. Newman Owiredu M, Newman L, Nzomo T, Kafando GC, Sanni S, Shaffer N, et al. Elimination of mother-to-child transmission of HIV and syphilis: a dual approach in the African region to improve quality of antenatal care and integrated disease control. Int J Gynecol Obstet. 2015;130:S27-S3.

32. Herlihy J, Hamomba L, Bonawitz R, Coggin CE, Sambambi K, Musonda B, et al. Implementation and operational research: integration of EMTCT and antenatal services improves combination antiretroviral therapy uptake for HIVpositive pregnant women in southern Zambia: a prototype for option B+? J AIDS. 2015;70(4):e123-9. https://doi.org/10.1097/QAl.0000000000000760.

\section{Ready to submit your research? Choose BMC and benefit from:}

- fast, convenient online submission

- thorough peer review by experienced researchers in your field

- rapid publication on acceptance

- support for research data, including large and complex data types

- gold Open Access which fosters wider collaboration and increased citations

- maximum visibility for your research: over $100 \mathrm{M}$ website views per year

At BMC, research is always in progress.

Learn more biomedcentral.com/submissions 